\title{
Visual Fixation in Human Newborns Correlates with Extensive White Matter Networks and Predicts Long-Term Neurocognitive Development
}

\author{
Susanna Stjerna, ${ }^{1}$ Viljami Sairanen, ${ }^{1,4}$ Riitta Gröhn, ${ }^{1}$ Sture Andersson, ${ }^{2}$ Marjo Metsäranta, ${ }^{2}$ Aulikki Lano, ${ }^{3}$ \\ and $\mathbb{C S}^{\text {Sampsa Vanhatalo }}{ }^{1,2}$ \\ Departments of ${ }^{1}$ Clinical Neurophysiology, HUS Medical Imaging Center, and Neurological Sciences, ${ }^{2}$ Pediatrics, ${ }^{3}$ Child Neurology, and ${ }^{4}$ Physics, University \\ of Helsinki and Helsinki University Central Hospital, Helsinki 00029, Finland
}

Infants are well known to seek eye contact, and they prefer to fixate on developmentally meaningful objects, such as the human face. It is also known, that visual abilities are important for the developmental cascades of cognition from later infancy to childhood. It is less understood, however, whether newborn visual abilities relate to later cognitive development, and whether newborn ability for visual fixation can be assigned to early microstructural maturation. Here, we investigate relationship between newborn visual fixation (VF) and gaze behavior (GB) to performance in visuomotor and visual reasoning tasks in two cohorts with cognitive follow-up at $2(n=57)$ and 5 $(n=1410)$ years of age. We also analyzed brain microstructural correlates to VF $(n=45)$ by voxel-based analysis of fractional anisotropy (FA) in newborn diffusion tensor imaging. Our results show that newborn VF is significantly related to visual-motor performance at both 2 and 5 years, as well as to visual reasoning at 5 years of age. Moreover, good newborn VF relates to widely increased FA levels across the white matter. Comparison to motor performance indicated that early VF is preferentially related to visuocognitive development, and that early motor performance relates neither to white matter integrity nor to visuocognitive development. The present findings suggest that newborn VF is supported by brainwide subcortical networks and it represents an early building block for the developmental cascades of cognition.

Key words: attention; biomarker; DTI; early cognition; neonatal; visual function

\section{Introduction}

Neurocognitive development forms a cascade where few basic abilities, or cognitive building blocks, of an infant comprise the framework for later emerging more complex cognitive functions (Rose et al., 2008). These cascades have been intensively studied in infant cognitive research, and relevant developmental trajectories have been identified from as young as few months of age to school age (Rose et al., 2008; Braddick and Atkinson, 2011; Brooks and Meltzoff, 2015).

However, there is a global health and societal challenge to recognize building blocks of cognition much earlier in life, even immediately after birth, which would have direct implications to those $>10 \%$ of newborns worldwide who are born with signifi-

Received Dec. 18, 2014; revised Feb. 3, 2015; accepted Feb. 11, 2015.

Author contributions: S.A., M.M., A.L., and S.V. designed research;S.S., M.M., A.L., and S.V. performed research;

S.S., V.S., R.G., M.M., A.L., and S.V. analyzed data; S.S., V.S., R.G., A.L., and S.V. wrote the paper.

This study was supported financially by Academy of Finland Grant 253130, Juselius Foundation, Ylppö foundation, The Päivikki and Sakari Sohlberg Foundation, and by the European Community's Seventh Framework Programme European Community FP7-PEOPLE-2009-IOF, Grant agreement 254235. We thank Drs Timo Vartia, Anja Niemelä, and Juha Peltola for original data collection in Group 2 infants.

The authors declare no competing financial interests.

Correspondence should be addressed to Dr Sampsa Vanhatalo, BABA Center, Department of Children's Neurophysiology, Children's Hospital, Helsinki University Central Hospital, PO Box 280, 00029 HUS, Finland. E-mail: sampsa.vanhatalo@helsinki.fi.

DOI:10.1523/JNEUROSCI.5162-14.2015

Copyright $\odot 2015$ the authors $\quad 0270-6474 / 15 / 354824-06 \$ 15.00 / 0$ cant developmental risks, such as prematurity or birth asphyxia (Salmaso et al., 2014). Recognizing cognitive building blocks in the newborn would also bridge the neonatal gap, the unnecessary split between research on newborns and older infants. The neuroscientific rationale for the split has been the qualitative shift that takes place in many neuronal and behavioral functions a few weeks after term birth in the human (Guzzetta et al., 2005; Colonnese et al., 2010; Hanganu-Opatz, 2010).

There is extensive literature on the development and use of neonatal neurological assessment scales, which have evolved over decades from combining large sets of observations or tests into global estimates. These scales typically assess neuromotor impairment (for review, see Noble and Boyd, 2012), however, it has become increasingly clear that main individual and societal burden from newborn compromise arises from ensuing cognitive disabilities, many of which depend on visual abilities (Aarnoudse-Moens et al., 2009). Neuropsychological studies provide ample evidence for a link between compromised visual functions in later infancy and other later cognitive compromises (Rose et al., 2008; Braddick and Atkinson, 2011; Brooks and Meltzoff, 2015).

In this context, surprisingly little is known about the early origins of this visual cognitive cascade; i.e., how the fundamental visual abilities of a newborn will carry onto later cognitive functions. Both the everyday experience and the classical studies on newborn imitation (Suddendorf et al., 2013) show that newborns 
actively seek eye contact and fixate preferentially to certain geometric features, such as faces (Farroni et al., 2005). Innate visual orientation and fixation of this kind is now assumed to arise from large scale brain networks coordinated by superior colliculus, the crucial driver of many holistic cognitive operations (Cang and Feldheim, 2013).

We hypothesized that: (1) visual fixation ability of the newborn specifically correlates with later development of visionrelated cognitive performance, and (2) integrity of white matter networks is related to the interindividual differences in visual behavior among infants.

\section{Materials and Methods}

Participants

This study consisted of two independent newborns groups recruited prospectively for large clinical studies in Children's Hospital, University of Helsinki, Finland. Group 1 was the primary study cohort that underwent neuroimaging and neurodevelopmental follow-up until 2 years of corrected age. It originally included 85 consecutive extremely preterm infants [born before gestational age (GA) of 28 weeks], as well as 22 term controls recruited between May 2006 and September 2008. The present study included those 57 newborns (42 preterm and 15 full-term; 17 females) who had successfully undergone all tests reported here. Babies lost to follow-up did not differ significantly with respect to their newborn test scores [visual fixation (VF) Pearson Chi $=0.76, \mathrm{df}=2, p=0.679$; gaze behavior $(\mathrm{GB})$ Pearson $\mathrm{Chi}=2.26 \mathrm{df}=3, p=0.519]$. Group 2 served to validate the findings in a $\sim 30$ times larger cohort and over two times longer neurodevelopmental follow-up (Heinonen et al., 2008). This cohort (total $n=2193$, including 658 healthy controls) was population-based recruitment in 1985-1986 from the neonatal wards of seven maternity hospitals in Helsinki area, and it represents the whole spectrum of GA and neonatal adversities. For the present analysis, we included infants ( $n=1410$; 948 hospitalized [278 (19.8\%) of them preterms] and 462 controls) that were successfully followed up, and were not found with obvious congenital anomalies or chromosomal abnormalities. Both studies were approved by the relevant Ethics Committee of the Helsinki University Hospital, and all parents gave their informed consent.

\section{Newborn assessment}

Newborn assessments at term age [Group 1: mean $41.7 \pm 1.7$ (SD) weeks conceptional age; Group 2: mean $39.6 \pm 2.2$ weeks conceptional age] were performed in a dimly lit room after feeding, with the infant lying supine, supported at $30-45^{\circ}$ angle, in alert state (eyes open, observed motor activity, no crying). In both study groups, the best performance of the infant was recorded. The test can be repeated, if needed, until the clinician is subjectively convinced that the child is at the desired vigilance state and performing at his/her best. Notably, this may lead to somewhat better average performance measures than what could be found without repeating the test. However, this standard practice of clinical research is used to avoid underestimating infant's performance due to erratically fluctuating vigilance, which is the main challenge in all newborn studies.

Group 1. We extracted two items from the six item subsection called Orientation and Behavior in the standard Hammersmith Neonatal Neurological Examination scale (Guzzetta et al., 2005). The selected items give a qualitative estimate of VF and GB, which in the test form are named "visual orientation" and "alertness," respectively. For VF, we used the following rating: $1=$ will not respond to stimuli; $2=$ looks but briefly; $3=$ looks at stimuli but loses them; $4=$ keeps interest in stimuli; and $5=$ does not tire. For GB, we used the following rating: $1=$ does not follow or focus on stimuli; 2 = stills, focuses, follows to side but loses stimuli; 3 = follows horizontally and vertically, but no head turn; $4=$ follows horizontally and vertically and turns head; and $5=$ follows in a circle. We used the standard black and white bull's eye target presented in front of infant's face, moving first slowly horizontally, from side to side, then vertically, and finally in an arc. For comparison, we took movement score that assesses infant's ability to raise head while lying prone: $1=$ no response; 2 rolls head over but chin not raised; $3=$ raises chin and rolls the head; $4=$ brings head and chin up; and $5=$ brings and keeps head and chin up.

Group 2. We tested visual fixation with a red woolen ball that was slowly moved horizontally in the central field, and the performance was scored as good (focuses and follows $>30^{\circ}$ ) or poor (all the others). In addition, newborn spontaneous motor movements were qualitatively scored into three categories: $1=$ normal; $2=$ mildly abnormal; and $3=$ clearly abnormal.

\section{Neurodevelopmental outcome tests}

Group 1. The infants were assessed at 2 years of corrected age using the standard Griffiths Mental Developmental Scales, and we analyzed here the subscales with vision-related functions: eye-hand coordination (Gvmi; e.g., building bricks or drawing objects) and visual performance (Gvis; patchwork, puzzles). In addition, total locomotor score (Gmot) was taken to assess interactions between visual and motor domains.

Group 2. The infants were assessed at 5 years (56 months) of age using the Columbia Mental Maturity Scale that measures visual reasoning skills (ViR; section called "nonverbal cognitive reasoning skills"). Visualmotor integration (VMI) was assessed using Beery Visual-Motor Integration test (Beery, 1982) that assess copying of geometrical figures.

\section{MRI imaging and analysis}

Total of sixty infants (49 born preterm) were imaged using Philips Achieva 1.5T scanner (Philips Medical Systems) with an 8-channel phased array head coil. Whole brain diffusion tensor imaging (DTI) was performed using a single-shot echo planar imaging sequence in 15 noncollinear diffusion weighted directions three times for each subject. Used repetition time was the shortest possible; echo time: $58 \mathrm{~ms}$, slice thickness: $2 \mathrm{~mm}$, field-of-view: $224 \mathrm{~mm}$, matrix: $128 \times 128$ with voxel size $1.75 \times 1.75 \times 2 \mathrm{~mm}^{3}, b$ value: 700 , number of averages: 1 , and SENSE factor: 2 . After visual review, six datasets ( 5 preterm) were rejected due to severe motion artifacts.

Preprocessing included conversion of DTI data to 4D NIFTI files, corrections for motion and eddy currents using FMRIB's Software Library (FSL v5.0; Smith et al., 2004) Diffusion Toolbox (FDT v3.0), and creating individual brain masks with Brain Extraction Tool (BET v2.1). Diffusion tensors were estimated voxelwise using a robust RESTORE algorithm (Chang et al., 2005) as implemented in UCL Camino Diffusion MRI Toolkit (Cook et al., 2006) and the resulting tensor eigenvalues were used to calculate fractional anisotropy (FA) images. Tract Based Spatial Statistics (Smith et al., 2006; Smith and Nichols, 2009) workflow suggested in FSL's user guide with skeleton threshold 0.15 and study-specific target image was used to perform voxelwise analysis of 45 infants (35 preterm) that also had VF test information available. Spearman rank correlations were searched with FSL's randomize using ranked FA and VF values with ranked GA as covariants (Kersbergen et al., 2014). Group differences were also computed between infants with good versus poor VF result. Mean FA values within the skeleton were calculated in four symmetric regions-of-interest (ROIs; see Fig. 2): (1) posterior ROI ( $n=$ 7979 FA skeleton voxels), consisting of optic radiation and posterior limbs; (2) frontal ROI $(n=8154)$; (3) superior ROI $(n=8802)$, including middle part of superior longitudinal fasciculi; and (4) corpus callosum ROI $(n=4120)$, which was selected more strictly to only include midline white matter structures.

\section{Statistical analyses}

Statistical analyses were conducted in SPSS Statistics for Windows (v19.0; IBM) using ANOVA, MANOVA (models with multiple dependents), two independent samples $t$ test and Pearson $\chi^{2}$ test. In addition, we used categorical regression analysis with optimal scaling to search for underlying trends in relationships that may escape linear analysis. The outcome variable (GVMi) was defined in ordinal scale and the independent variable (VF) was defined in nominal scale to allow seeing possible nonmonotonic relationships as well. Significance level was set at $p<$ 0.05 .

\section{Results}

Half of the infants in Group 1 showed good fixations (VF score 4, $n=29$ ), and the other newborns either lost fixation (score 3; $n=$ 
A

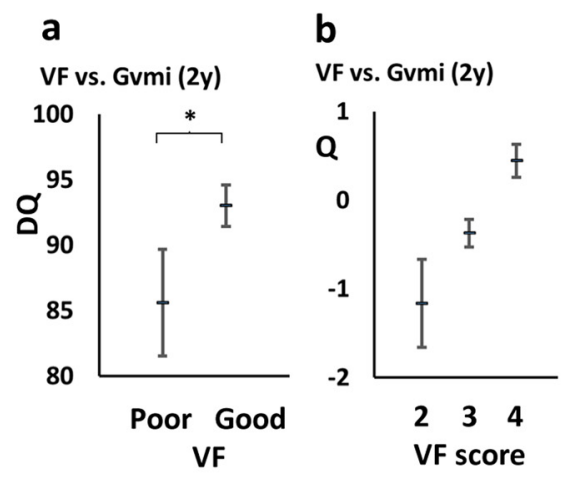

B

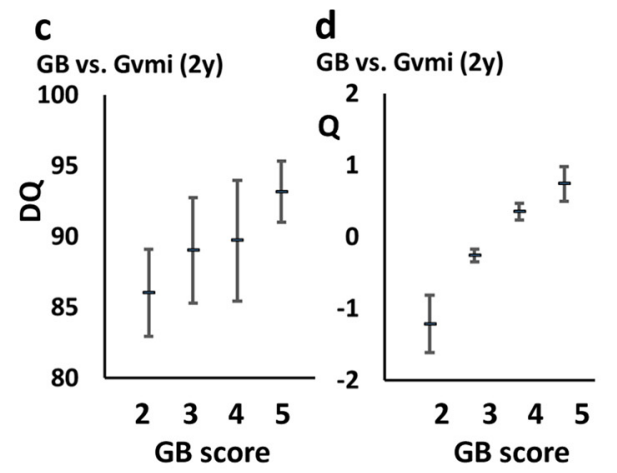

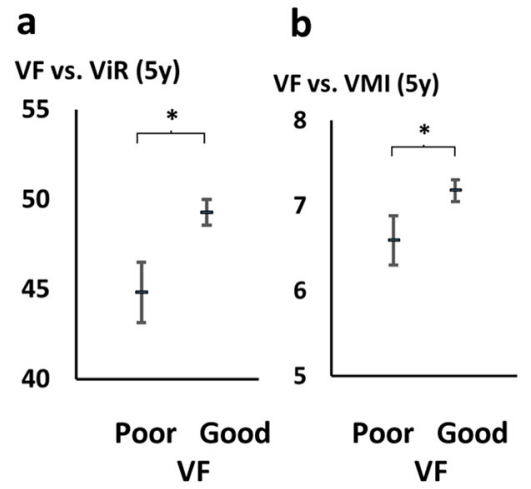

C
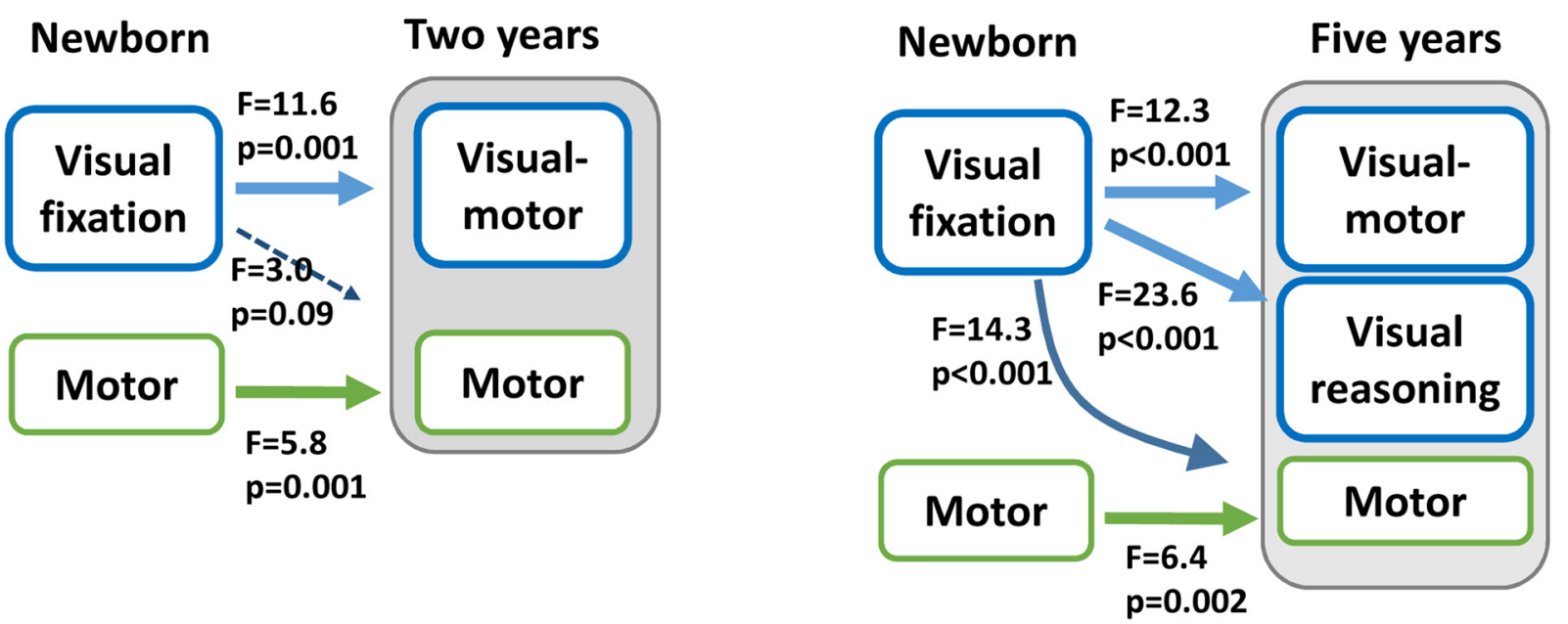

Figure 1. Relation of newborn VF and GB to neurocognitive outcomes at 2 and 5 years. $\boldsymbol{A}$, Gvmi at 2 years (Group 1 ) according to newborn VF and GB scores (mean \pm confidence interval $95 \%$ ). $\boldsymbol{A} \boldsymbol{b}, \boldsymbol{A d}$, Findings from categorical regression analysis (Q, quantifications; estimated $\pm 95 \%$ confidence intervals). $Q, Q$ uantifications of Gvmi. $\boldsymbol{B}$, ViR and VMI at 5 years (Group 2 ) according to newborn VF scores. C, Models combining visual and motor performance (left, Group 1; right, Group 2) show the preferential relationship from newborn VF to visual cognitive outcomes. DQ, Developmental quotient. Significant findings are indicated with an asterisk.

25), or only looked briefly without genuine fixation (score $2 ; n=$ 3 ). We hence combined scores into two groups, good and poor $\mathrm{VF}$, respectively. GB findings were analyzed with original scores due to wider variability ( $n=8$ for score $2 ; n=16$ for score $3, n=$ 27 for score 4 , and $n=6$ for score 5 ). Comparison of VF scores according to background details showed no difference between preterm and full-term subgroups (Pearson $\chi^{2}=1.47, \mathrm{df}=2, p=$ 0.48 ) or genders (Pearson $\chi^{2}=4.28, \mathrm{df}=2, p=0.118$ ). Further analysis showed that neither gender or full-term birth was significantly associated to GVmi when added in to the same model with $\mathrm{VF}$, hence subsequent analysis was performed considering the whole Group 1 together. In the Group 2, good VF was seen more often in girls than boys (Pearson $\chi^{2}=18.54, \mathrm{df}=1 p<0.001$ ), as well as in controls compared with hospitalized infants (Pearson $\left.\chi^{2}=9.60, \mathrm{df}=2 p<0.01\right)$. However, combined models showed that VF has independent relationship to outcomes (ViR: VF main effect $F=10.28, \mathrm{df}=1, p=0.001$; Vmi: VF main effect $F=5.51$, $\mathrm{df}=1, p=0.019$ ), even after adding gender and hospitalization status.

Newborn visual abilities predict visual-motor performance at 2 years

Newborns with good VF showed significantly better Gvmi performance at 2 years of age compared with those with poor VF $\left(F=11.3\right.$, df $=1, p=0.001, R^{2}$ adj $=0.16$; Fig. $\left.1 A a\right)$. The difference in mean Gvmi scores between the groups was notable (observed means poor $=85.9$, good $=93.0$ ) and overall amount of shared variance was at least moderate $\left(R^{2}\right.$ adj $\left.=0.16\right)$. Moreover, VF was independently and significantly related to Gvmi ( $F=10,775, \mathrm{df}=1, p=0.002)$ even if GA was added to the model. We also analyzed post hoc the three original VF scores for a possible scaling relationships with later Gvmi by modeling it using categorical regression analysis with optimal scaling, and we found the relationship significant $\left(\beta=0.48, p=0.003 ; R^{2}\right.$ adj $=$ 0.19; Fig. $1 A b)$. Newborns with different GB scores showed no significant differences in Gvmi results at 2 years without $(F=$ $0.73, \mathrm{df}=3, p=0.54$; Fig. $1 A c)$ or with $\mathrm{GA}(F=0.39, \mathrm{df}=3, p=$ $0.76)$. However post hoc inspection using categorical regression with optimal scaling suggested a modestly significant relation$\operatorname{ship}\left(\beta=0.40, p=0.06, R^{2}\right.$ adj $=0.09$; Fig. $\left.1 A d\right)$.

Newborn visual abilities are not reflected in visual performance at 2 years

Comparison of Gvis results at 2 years showed no significant difference between newborns who had good versus poor VF without $(F=2.57, \mathrm{df}=1, p=0.12)$ or with gestation age $(F=2.29, \mathrm{df}=$ $1, p=0.14)$. Further categorical regression analysis using all three VF scores was nonsignificant as well $(F=1.40, \mathrm{df}=3, p=0.25)$. In addition, infants with different newborn GB showed no significant differences in Gvis results at 2 years neither alone $(F=0.44$, 


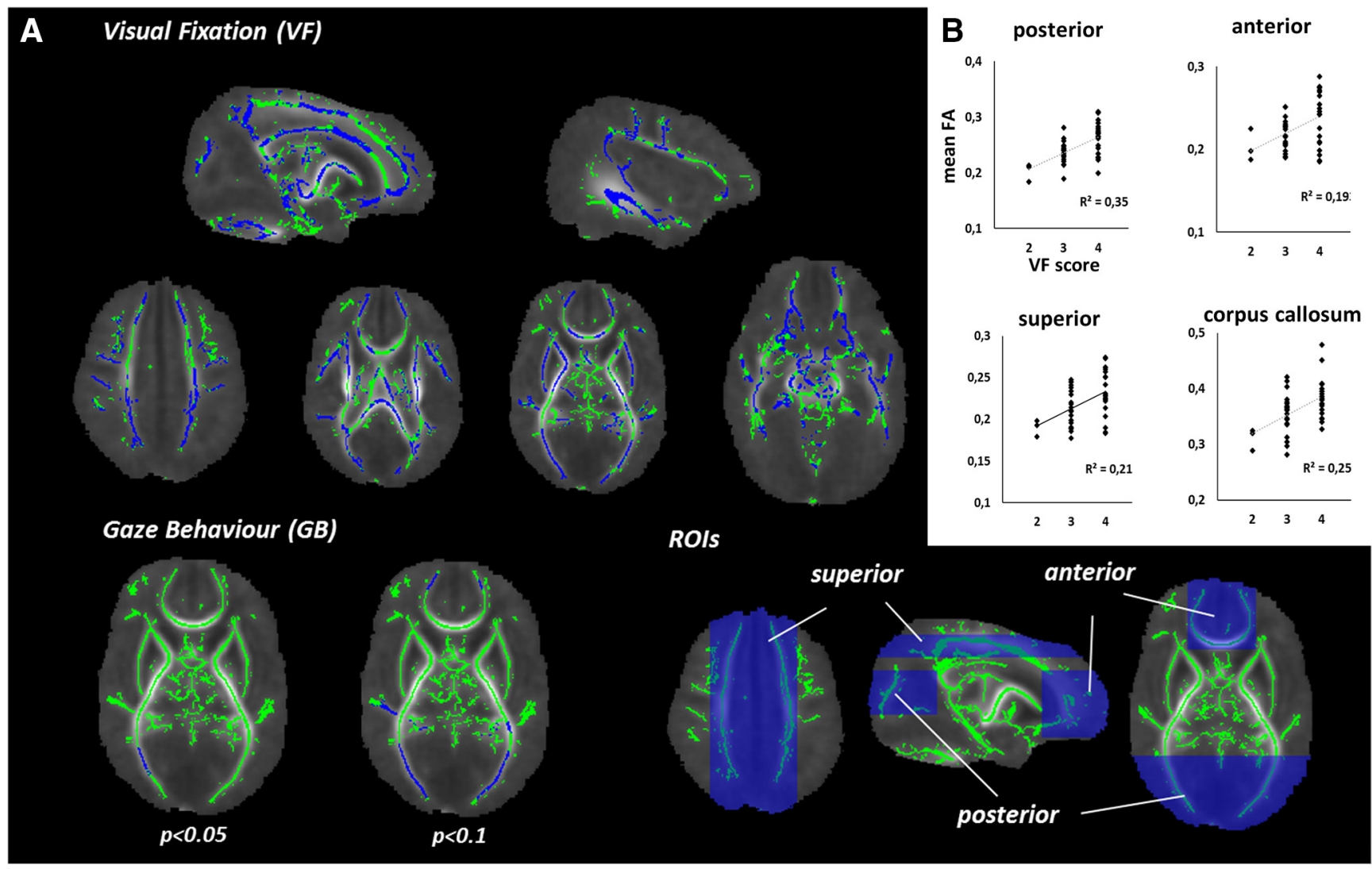

Figure 2. Structural correlates of newborn VF and GB. $A$, White matter skeleton is depicted in green, and voxels with significant correlation to VF (top) or GB (bottom) are depicted in blue. $B$, Mean $F A$ values of FA skeleton voxels within each region of interest (ROI, blue boxes).

$\mathrm{df}=3, p=0.73)$ or in a model with GA $(F=0.68, \mathrm{df}=3, p=$ $0.57)$. Hence, the tested visual functions in newborns do not appear to carry on to Gvis performance at 2 years.

\section{Newborn visual fixation relates to wide changes in white matter integrity}

Voxel-based comparison of infants with different VF performance disclosed statistically significant differences in FA values throughout the white matter. Almost half $(48 \%$; $n=62,535$ voxels) of the voxels in the FA skeleton exhibited significantly higher FA values in the infants with good VF. The differences were spread over all areas (Fig. 2) with no visually apparent spatial emphasis, neither notable asymmetry between hemispheres (left $47 \%$; right 49\%). Analysis of mean FA level ( $n=45$ infants) in our deliberately unselective, large ROIs showed mutually comparable increases with better VF; frontal: $r=0.43, p=0.003$; posterior: $r=0.54, p<0.001$; superior: $r=0.47, p=0.001$; corpus callosum: $r=0.52, p<0.001$. The global nature of FA findings was also supported by the significant correlations between all ROIs ( $p<0.001$ for all comparisons; $r$ ranging from 0.51 to 0.87 ). Correlations with newborn GB were much weaker, with only $0.2 \%$ of voxels (Fig. 2 ) found significant, located within the optic radiation. A post hoc analysis with higher significance threshold $(p<0.1)$ showed markedly more voxels $(11 \%$; $n=14,590$ voxels), around the same areas, suggesting that also GB has microstructural correlates, however, within more delimited locations.

\section{Newborn visual fixation predicts visual functions at 5 years} Group 2 was used to validate findings in a much larger dataset with nearly 30 times more newborns, more diverse backgrounds, and much longer cognitive follow-up. Prior studies have indicated developmental tailing off of early effects in developmental cascades (Claas et al., 2011). In this context, we found it particularly interesting that visual-motor performance was significantly better at 5 years in children with good newborn VF $(t=3.511$, $\mathrm{df}=1400, p<0.001$, mean VMI $7.2 \pm 2.3$ vs $6.6 \pm 2.2$ in good vs poor VF, respectively; Fig. $1 \mathrm{Ba}$ ). Moreover, visual reasoning was also significantly better in children who had good VF when newborn $(t=4.875, \mathrm{df}=1408, p<0.001$; mean ViR points $49.3 \pm$ 12.3 vs $44.8 \pm 12.6$ in good vs poor VF, respectively; Fig. $1 B b$ ). Finally, we assessed how much inclusion of GA into the model would affect prediction by newborn VF. As expected, GA itself was predictive $(\mathrm{ViR} F=1.92, \mathrm{df}=21, p=0.007$; VMI $F=2.25$, $\mathrm{df}=21, p=0.001)$, but VF also retained an independent effect on $\operatorname{ViR}(F=2.944, \mathrm{df}=1, p=0.086$; VMI was no more significant $)$.

Modality preference in the early neurocognitive development In addition to above findings, it could be also possible that early VF is a more general surrogate marker of development, especially because VF alone was found to covariate with later motor performance (Gmot; $\left.F=7.27, \mathrm{df}=1, p<0.01, R^{2}=0,10\right)$. Therefore we used models with combined performance data (Fig. 1C): In Group 1, VF was significantly related GVmi, but only marginally to motor functions; however, newborn motor performance was only significantly related to later motor function. This model accounted for at least moderate amount of the variance $(\mathrm{GVmi}$ scores, $R^{2}$ adj $=0.19$; Gmot scores, $R^{2}$ adj $\left.=0.42\right)$. These findings were comparable in Group 2 where newborn VF was significantly related to VMI and Vir, but also to the motor performance. However, newborn motor performance was significantly related only 
to motor performance, but not to ViR or VMI at 5 years. These findings together suggest preferential prediction of later cognition by newborn VF, although VF may partly also predict later motor performance; however, newborn motor performance is not predictive of later visual cognition. To complement these findings, we also studied structural correlates of newborn motor performance, and found none of the voxels in the whole FA skeleton to significantly correlate with newborn motor performance scores.

\section{Discussion}

Here we report that newborn's visual abilities show highly significant relationship with white matter integrity and later emergence of visual cognitive functions. Our observation is in full agreement with prior studies that have indicated relative importance of early visual functions over shorter developmental time scales or in smaller study populations (Wallace et al., 1995; Cioni et al., 2000; Ricci et al., 2011). Present findings extend prior knowledge by showing that already the newborn ability to maintain fixation, or visual attention, is significantly related later visual cognition, and this ability relates to remarkably wide correlates in brain white matter microstructure.

The cognitive cascades from basic abilities in infants to later executive functions in childhood are extensively explored beginning from later infancy onwards (Rose et al., 2008; Brooks and Meltzoff, 2015); however, developmental trajectories beginning from the neonatal period are much less studied. Such work is broadly challenged by the qualitative shift after neonatal period at multiple levels of brain functions, ranging from molecular mechanisms (Vanhatalo et al., 2005; Hanganu-Opatz, 2010) to neuronal network behaviors (Colonnese et al., 2010; Omidvarnia et al., 2014), as well as in neurobehavioral performance (Guzzetta et al., 2005). Neurodevelopmentally, this represents the shift from precritical period with experience-independent maturation to critical period with increasingly stronger experience-dependence (Feller and Scanziani, 2005; Espinosa and Stryker, 2012). It is conceivable, that the earliest fundamental brain mechanism required at the onset of experience-dependent development include sensory attention, especially vision, the key sense in later cognitive development (cf. Johnson and de Haan, 2010).

Our findings are in agreement with prior studies reporting relationship between newborn visual functions and FA levels within optic radiations (Bassi et al., 2008; Groppo et al., 2014); however, our whole brain analysis discloses significantly wider structural correlates to newborn visual abilities, at least to VF. Our diffuse, near global changes in white matter structures do not directly confirm any particular functional neuroanatomical entity. However, comparison of our findings to recent experimental work on the early neurocognitive networks offers an intriguing anatomical parallel: During early phases of neurocognitive development, tectal structures including superior colliculus (SC) (Johnson and de Haan, 2010; Maior et al., 2012) are thought to control brain wide networks (Krauzlis et al., 2013), which as a whole overlap largely with our present FA findings. The earliest visual fixation and preference to geometric features, in particular to faces, is mediated subcortically by tectal level rather than by striatal pathways. Recent studies suggest SC seats the networks of early multisensory and cross-modal integration (Filippetti et al., 2013) via overlaid topographic maps, in addition to SC receiving direct visual input, subserving oculomotor control, and providing a central role in early attentional modulation (Cang and Feldheim, 2013; for review, see Krauzlis et al., 2013). Together, our findings are compatible with an idea that the newborn VF links to cognitive development by relying on this early neonatal connectome (Ball et al., 2014; van den Heuvel et al., 2014): first, integrity in those subcortical networks is necessary for the earliest visual fixation and attention. Second, the same networks operate as the fundamental core for later emerging higher cognitive functions. Our observed lack of relationships between newborn motor performance and brain microstructure or visual cognitive development are both in agreement with the idea that SC-related wide networks are preferentially implicated in cognitive development.

Visual function as a part of newborn neurological screening is routinely done by qualitative assessment of VF and GB akin to our study (Guzzetta et al., 2005); however, more complex visual examination scales have also been developed (Cioni et al., 2000; Ricci et al., 2011). The presently assessed VF alone showed stronger prediction of later visual performance than GB, a more complex visual performance. Although many fundamental visual abilities can be observed already at early preterm age (Ricci et al., 2010), we are not aware of strong prior evidence for their relationship to cognitive development before later infancy (Johnson and de Haan, 2010). Intriguingly, a detailed comparison to prior literature (Cioni et al., 2000; Ricci et al., 2011) does not suggest any better developmental prediction by the composite scores from the published, much more elaborated tests of visual function.

In conclusion, the present observations are fully compatible with the idea that newborn's ability to VF likely comprises a significant early building block in the upcoming cascades of higher cognitive development. The underlying neurocognitive mechanisms deserve extensive studies; however, we also envision a possibility to design newborn cognitive biomarkers based on better quantitation of infant's visual behavior. Such advance would hold promise for progressing mechanistic understanding of partitioned cognitive development, as well as for benchmarking future early therapeutic interventions.

\section{References}

Aarnoudse-Moens CS, Weisglas-Kuperus N, van Goudoever JB, Oosterlaan J (2009) Meta-analysis of neurobehavioral outcomes in very preterm and/or very low birth weight children. Pediatrics 124:717-728. CrossRef Medline

Ball G, Aljabar P, Zebari S, Tusor N, Arichi T, Merchant N, Robinson EC, Ogundipe E, Rueckert D, Edwards AD, Counsell SJ (2014) Rich-club organization of the newborn human brain. Proc Natl Acad Sci U S A 111:7456-7461. CrossRef Medline

Bassi L, Ricci D, Volzone A, Allsop JM, Srinivasan L, Pai A, Ribes C, Ramenghi LA, Mercuri E, Mosca F, Edwards AD, Cowan FM, Rutherford MA, Counsell SJ (2008) Probabilistic diffusion tractography of the optic radiations and visual function in preterm infants at term equivalent age. Brain 131:573-582. CrossRef Medline

Beery KE (1982) Revised administration, scoring and teaching manual for the developmental test of visual-motor integration. Cleveland:Toronto: Modern Curriculum.

Braddick O, Atkinson J (2011) Development of human visual function. Vision Res 51:1588-1609. CrossRef Medline

Brooks R, Meltzoff AN (2015) Connecting the dots from infancy to childhood: A longitudinal study connecting gaze following, language, and explicit theory of mind. J Exp Child Psychol 130:67-78. CrossRef Medline

Cang J, Feldheim DA (2013) Developmental mechanisms of topographic map formation and alignment. Annu Rev Neurosci 36:51-77. CrossRef Medline

Chang LC, Jones DK, Pierpaoli C (2005) RESTORE: robust estimation of tensors by outlier rejection. Magn Reson Med 53:1088-1095. CrossRef Medline

Cioni G, Bertuccelli B, Boldrini A, Canapicchi R, Fazzi B, Guzzetta A, Mercuri E (2000) Correlation between visual function, neurodevelopmental outcome, and magnetic resonance imaging findings in infants with periventricular leucomalacia. Arch Dis Child Fetal Neonatal Ed 82:F134140. CrossRef Medline 
Claas MJ, de Vries LS, Bruinse HW, van Haastert IC, Uniken Venema MM, Peelen LM, Koopman C (2011) Neurodevelopmental outcome over time of preterm born children $\leq 750 \mathrm{~g}$ at birth. Early Hum Dev 87:183191. CrossRef Medline

Colonnese MT, Kaminska A, Minlebaev M, Milh M, Bloem B, Lescure S, Moriette G, Chiron C, Ben-Ari Y, Khazipov R (2010) A conserved switch in sensory processing prepares developing neocortex for vision. Neuron 67:480-498. CrossRef Medline

Cook PA, Bai Y, Nedjati-Gilani SKKS, Seunarine KK, Hall MG, Parker GJ, Alexander DC (2006) Camino: open-source diffusion-MRI reconstruction and processing. In: 14th Scientific Meeting of the International Society for Magnetic Resonance in Medicine, Seattle, Washington, May.

Espinosa JS, Stryker MP (2012) Development and plasticity of the primary visual cortex. Neuron 75:230-249. CrossRef Medline

Farroni T, Johnson MH, Menon E, Zulian L, Faraguna D, Csibra G (2005) Newborns' preference for face-relevant stimuli: effects of contrast polarity. Proc Natl Acad Sci U S A 102:17245-17250. CrossRef Medline

Feller MB, Scanziani M (2005) A precritical period for plasticity in visual cortex. Curr Opin Neurobiol 15:94-100. CrossRef Medline

Filippetti ML, Johnson MH, Lloyd-Fox S, Dragovic D, Farroni T (2013) Body perception in newborns. Curr Biol 23:2413-2416. CrossRef Medline

Groppo M, Ricci D, Bassi L, Merchant N, Doria V, Arichi T, Allsop JM, Ramenghi L, Fox MJ, Cowan FM, Counsell SJ, Edwards AD (2014) Development of the optic radiations and visual function after premature birth. Cortex 56:30-37. CrossRef Medline

Guzzetta A, Haataja L, Cowan F, Bassi L, Ricci D, Cioni G, Dubowitz L, Mercuri E (2005) Neurological examination in healthy term infants aged 3-10 weeks. Biol Neonate 87:187-196. CrossRef Medline

Hanganu-Opatz IL (2010) Between molecules and experience: role of early patterns of coordinated activity for the development of cortical maps and sensory abilities. Brain Res Rev 64:160-176. CrossRef Medline

Heinonen K, Räikkönen K, Pesonen AK, Kajantie E, Andersson S, Eriksson JG, Niemelä A, Vartia T, Peltola J, Lano A (2008) Prenatal and postnatal growth and cognitive abilities at 56 months of age: a longitudinal study of infants born at term. Pediatrics 121:e1325-e1333. CrossRef Medline

Johnson MH, de Haan M (2010) Vision, orienting and attention. In: Developmental Cognitive Neuroscience, Ed 3 (Hoboken HJ, ed). Oxford: Wiley-Blackwell.

Kersbergen KJ, Leemans A, Groenendaal F, van der Aa NE, Viergever MA, de Vries LS, Benders MJ (2014) Microstructural brain development between 30 and 40weeks corrected age in a longitudinal cohort of extremely preterm infants. Neuroimage 103:214-224. CrossRef Medline

Krauzlis RJ, Lovejoy LP, Zénon A (2013) Superior colliculus and visual spatial attention. Annu Rev Neurosci 36:165-182. CrossRef Medline

Maior RS, Hori E, Uribe CE, Saletti PG, Ono T, Nishijo H, Tomaz C (2012) A role for the superior colliculus in the modulation of threat responsiveness in primates: toward the ontogenesis of the social brain. Rev Neurosci 23:697-706. Medline

Noble Y, Boyd R (2012) Neonatal assessments for the preterm infant up to 4 months corrected age: a systematic review. Dev Med Child Neurol 54: 129-139. CrossRef Medline

Omidvarnia A, Fransson P, Metsäranta M, Vanhatalo S (2014) Functional bimodality in the brain networks of preterm and term human newborns. Cereb Cortex 24:2657-2668. CrossRef Medline

Ricci D, Romeo DM, Serrao F, Gallini F, Leone D, Longo M, Albamonte E, Romeo MG, Mazzone D, Romagnoli C, Cowan F, Mercuri E (2010) Early assessment of visual function in preterm infants: how early is early? Early Hum Dev 86:29-33. CrossRef Medline

Ricci D, Romeo DM, Gallini F, Groppo M, Cesarini L, Pisoni S, Serrao F, Papacci P, Contaldo I, Perrino F, Brogna C, Bianco F, Baranello G, Sacco A, Quintiliani M, Ometto A, Cilauro S, Mosca F, Romagnoli C, Romeo MG, et al. (2011) Early visual assessment in preterm infants with and without brain lesions: correlation with visual and neurodevelopmental outcome at 12 months. Early Hum Dev 87:177-182. CrossRef Medline

Rose SA, Feldman JF, Jankowski JJ, Van Rossem R (2008) Cognitive cascade in infancy: pathways from prematurity to later mental development. Intelligence 36:367-378. CrossRef Medline

Salmaso N, Jablonska B, Scafidi J, Vaccarino FM, Gallo V (2014) Neurobiology of premature brain injury. Nat Neurosci 17:341-346. CrossRef Medline

Smith SM, Jenkinson M, Woolrich MW, Beckmann CF, Behrens TE, Johansen-Berg H, Bannister PR, De Luca M, Drobnjak I, Flitney DE, Niazy RK, Saunders J, Vickers J, Zhang Y, De Stefano N, Brady JM, Matthews PM (2004) Advances in functional and structural MR image analysis and implementation as FSL. Neuroimage 23:S208-S219. CrossRef Medline

Smith SM, Jenkinson M, Johansen-Berg H, Rueckert D, Nichols TE, Mackay CE, Watkins KE, Ciccarelli O, Cader MZ, Matthews PM, Behrens TE (2006) Tract-based spatial statistics: voxelwise analysis of multi-subject diffusion data. Neuroimage 31:1487-1505. CrossRef Medline

Smith SM, Nichols TE (2009) Threshold-free cluster enhancement: addressing problems of smoothing, threshold dependence and localisation in cluster inference. Neuroimage 44:83-98. CrossRef Medline

Suddendorf T, Oostenbroek J, Nielsen M, Slaughter V (2013) Is newborn imitation developmentally homologous to later social-cognitive skills? Dev Psychobiol 55:52-58. CrossRef Medline

van den Heuvel MP, Kersbergen KJ, de Reus MA, Keunen K, Kahn RS, Groenendaal F, de Vries LS, Benders MJ (2014) The neonatal connectome during preterm brain development. Cereb Cortex. Advance online publication. Retrieved May 15, 2014. CrossRef Medline

Vanhatalo S, Palva JM, Andersson S, Rivera C, Voipio J, Kaila K (2005) Slow endogenous activity transients and developmental expression of $\mathrm{K}+-\mathrm{Cl}-$ cotransporter 2 in the immature human cortex. Eur J Neurosci 22:27992804. CrossRef Medline

Wallace IF, Rose SA, McCarton CM, Kurtzberg D, Vaughan HG Jr (1995) Relations between infant neurobehavioral performance and cognitive outcome in very low birth weight preterm infants. J Dev Behav Pediatr 16:309-317. Medline 